\title{
RELEITURA DE UM GOLPE: REFLEXÕES A PARTIR DAS CONTRIBUIÇÕES DE WANDERLEY GUILHERME DOS SANTOS
}

\author{
Coup rereading: reflections from the contributions of Wanderley Guilherme dos Santos \\ Releyendo un golpe de Estado: reflexiones de las contribuciones de Wanderley Guilherme \\ dos Santos
}

Received: $\mathrm{may} / 2020$

Accepted: june/2020

Available online: june/2020

Flávia Sanches de Carvalho, doutoranda em Ciência Política, Universidade Federal de São Carlos, Brasil. E-mail: flaviasanches81@gmail.com

\begin{abstract}
Resumo: O presente artigo é um ensaio que objetiva trazer algumas reflexões sobre o contexto que antecede o golpe 1964 e a inserção do pensamento de Wanderley Guilherme dos Santos no contexto social, político e histórico do Brasil. Refletir sobre este autor e sua obra - notadamente o livro Sessenta e quatro: anatomia da crise - é importante, uma vez que ela apresenta uma posição antagônica ao pensamento cepalino e desenvolvimentista, em especial com seu maior representante brasileiro, Celso Furtado e lança luz aos dilemas vividos na política nacional na contemporaneidade.
\end{abstract}

Palavras-chave: Wanderley Guilherme dos Santos; Golpe de 1964; Paralisia decisória.

\begin{abstract}
The present article is an essay that aims to bring some reflections on the context that precedes the 1964 coup and the insertion of the thought of Wanderley Guilherme dos Santos in the social, political and historical context of Brazil. Reflecting on this author and his work - notably the book Sixty-four: anatomy of the crisis - is important, since it presents an antagonistic position to CEPAL and developmentalist thinking, especially with its greatest Brazilian representative, Celso Furtado and sheds light on the dilemmas experienced in contemporary national politics.
\end{abstract}

Keywords: Wanderley Guilherme dos Santos; 1964 coup; Decision-making paralysis.

RBPPD/BRJPD | Vol. 2 | n. 2 | p. 1-17, 2020. 
Resumen: El presente artículo es un ensayo que tiene como objetivo traer algunas reflexiones sobre el contexto que precede al golpe de estado de 1964 y la inserción del pensamiento de Wanderley Guilherme dos Santos en el contexto social, político e histórico de Brasil. Reflexionar sobre este autor y su trabajo, especialmente el libro Sesenta y cuatro: anatomía de la crisis, es importante, ya que presenta una posición antagónica con la CEPAL y el pensamiento desarrollista, especialmente con su mayor representante brasileño, Celso Furtado, y arroja luz sobre el dilemas experimentados en la política nacional contemporánea.

Palabras clave: Wanderley Guilherme dos Santos, Golpe de Estado de 1964; parálisis de toma de decisiones.

\section{INTRODUÇÃO}

Wanderley Guilherme dos Santos faz parte de uma geração de intelectuais que teve sua obra interlaçada à trajetória política, social e econômica do país. Falando especificamente do período pré e pós 1964, o autor se destaca em dois momentos distintos, primeiramente se antecipando, no artigo "Quem dará o golpe no Brasil”, publicado em fevereiro de 1962, no qual, não só anteviu a queda do então presidente João Goulart, como também um provável golpe, que se confirmaria em 1964, com a ascensão dos militares ao poder. E, em um segundo momento, em 1969, quando escreveu em inglês a obra Sessenta e Quatro: anatomia da crise, traduzida para o português apenas em 1986. Nesta última obra ele fala sobre as causas do golpe militar de 1964, trazendo uma métrica de estudo, análise e contextualização sobre o processo político de uma forma inédita até então. Para Limonge (1987), por exemplo, a obra do autor é essencial e renovadora para se entender o processo político nacional, deixando claro que, embora o Guilherme dos Santos busque explicar a crise de 1964, a importância de sua obra está para além, lançando luz ao processo político de forma inédita até o momento, apelando para um redirecionamento das pesquisas sobre a evolução do sistema político pós 1946.

Resumidamente, a tese do autor explicita a impossibilidade de se falar em nacionaldesenvolvimentismo quando, na prática, as decisões estão nas relações entre executivo, legislativo e judiciário ou entre capital internacional e nacional ou, ainda, entre as frações de classes que existem dentro da sociedade brasileira. A chave utilizada por Wanderley Guilherme dos Santos está focada nos campos da ação e das instituições. Para ele: 
(...) mediante a descrição de sistemas polarizados, que uma crise de paralisação decisória torna-se o resultado mais provável do confronto político quando os recursos de poder se dispersam entre atores radicalizados em suas posições, de tal forma que estabelece o que denomino de equilíbrio político. Parto então do diagnóstico de que o período de 1961-1964 foi marcado justamente pela transformação de um sistema político razoavelmente operacional em um sistema incapaz de produzir decisões sobre as questões mais prementes à época (SANTOS, 1986, p. 10).

Importante ressaltar que, mesmo mais de cinco décadas depois, as origens, o contexto, os impulsos geradores do golpe de 64 , seus atores, protagonistas e forças que o resignaram são parte cada vez mais presente do debate político atual, sendo essa, em última instância, a motivação maior desse trabalho. Neste sentido, faz-se necessário, enquanto digressão histórica, recuperar os movimentos mais gerais pelos quais passou o país para, em seguida, fazer breves considerações sobre Guilherme dos Santos.

\section{PROCESSOS HISTÓRICOS E TRAJETÓRIA NACIONAL}

Os militares, como força política ascende pós proclamação da república, passaram a ter um papel fundamental no país, pois tratava de uma camada da classe média alocada no Estado. É fato que até a proclamação da república não havia uma organização militar propriamente constituída, somente após a Guerra do Paraguai que a instituição dividirá seu contingente entre os soldados especializados e os demais, isto é, "científicos e tarimbeiros" (BRESSERPEREIRA, 2015).

O período que se inicia a partir de 1920 é caracterizado, majoritariamente pela falta de controle central em muitas regiões da América Latina, com destaque para o Brasil, que tinha um governo nacional com responsabilidade nominal para exercer controle, que era desempenhado por um alto grau de federalismo que acabou por limitar os poderes nominais das autoridades centrais como observado por Whitehead (2009). 
Nesse contexto emerge a capacidade de organização do movimento tenentista, a partir de 1922, que, pela primeira vez, demonstra a capacidade de organização e interlocução da classe e a associação entre civis e militares, rumo a realização de uma revolução burguesa. José Murilo de Carvalho (2002), classifica o movimento tenentista, encabeçado pelos jovens oficiais do exército, como estritamente militar e corporativista, que obteve simpatia por atacar as oligarquias política e rurais estaduais. Para Carvalho (2002) a busca pela expansão dos direitos civis e políticos do movimento e o ataque contra as oligarquias rurais foi responsável pelo apoio dado ao movimento por parte expressiva da sociedade brasileira. Todavia, ele também salienta que o movimento não contava com o envolvimento popular e que a concepção política dos tenentes contemplava o assalto ao poder como tática de oposição, e que manteriam essa postura golpista alheia à mobilização popular, mesmo pós 1930. A crise de 29 teve impactos generalizados e complexos no Brasil. Com ela, desestruturam-se as bases de sustentação do modelo primário-exportador nacional, com impactos diferenciados sobre todas as regiões brasileiras, que segundo Joelson Gonçalves de Carvalho,

(...) terá impactos de extrema relevância para o conjunto da economia nacional pós-30. Do ponto de vista interno, quebra-se a "espinha dorsal" do modelo primário-exportador, limitando bastante o poder econômico e político da então elite dominante. Do ponto de vista internacional, as restrições causadas pela crise, em especial as limitações de créditos e as dificuldades de importação, conferem à industrialização nacional prioridade para a política econômica, na busca de maior autonomia econômica (CARVALHO, 2004, p. $15)$.

Para Vera Alves Cepêda (2004) a chave que se abre nos anos 1930, marca significativas mudanças no Estado e na sociedade brasileira, principalmente no rompimento com a lógica do latifúndio patriarcal mercantilista, para a autora:

Durante as décadas de 1930 e 1940 ocorreu um conjunto significativo de transformações no campo do pensamento político, social e econômico brasileiro, bem como uma redefinição da relação do papel do Estado e de suas funções. Destaco como exemplares desse período e dessa nova conformação a ascendente defesa da industrialização como estratégia de modernização e 
consolidação nacional (em substituição à vocação mercantil-exportadora), a emergência de marcos regulatórios no campo do direito do trabalho e dos direitos sociais, a inclinação para fortalecimento do protagonismo estatal via planejamento e planejamento da mudança social (CEPÊDA, 2004, p. 1).

A industrialização no Brasil tem seu arranque nos anos 1930 com o rompimento com as bases agrárias, tradicionais e de caráter basicamente colonial, porém, identifica que esse processo de industrialização, mesmo em pequena escala, já tem seus primeiros passos a partir de meados do século XIX (BRESSER-PEREIRA, 2015).

As significativas mudanças pró industrialização ocorrem na virada do século XIX para o XX, puxadas pelo estado de São Paulo. Todavia, "O Estado era fraco, excessivamente dependente dos proprietários de terra e de uma classe política liberal alienada para poder realizar essa tarefa" (BRESSER-PEREIRA, 2015, p. 102). Nesse sentido, é fundamental destacar o surgimento de uma classe média mais atuante que toma corpo no final do século XIX. Sua solidificação contribuiu sobremaneira para substituir as oligarquias rurais tradicionais e foram fundamentais para a guinada para a Revolução de 1930.

No Brasil, a revolução de 1930, que pôs fim à notoriamente invertebrada "República Velha", poder ser vista em retrospectiva como um passo decisivo rumo à construção de uma verdadeira autoridade central que pudesse exercer um controle efetivo sobre todo esse vasto território (...) (WHITEHEAD, 2009, p. 39)

Grosso modo, para o pensamento getulista apenas o Estado contava, um Estado que se apoiasse nas instituições que ele mesmo tinha criado à sua imagem e semelhança. Essa nuvem de fumaça que é lançada por Vargas em um ambiente populista vai criar um Estado demiurgo numa cadeia de forças junto a diversos atores da sociedade brasileira. As frações de classe que vão operar no tecido e na cultura política da sociedade brasileira, que começam a se organizar de 1930 a 1964, saem do macro política e enveredam numa leitura fina de atores, de conjuntura, de aliança, de externalidades, etc. 
Sendo assim, é fundamental a chave de análise que envolve a ruptura com as oligarquias agrárias e a consolidação de uma revolução industrial, tardia, mas funcional ao capitalismo brasileiro, com o protagonismo de Getúlio Vargas, e um pacto nacional-popular que, de 1930 a 1959, foi caracterizado pelo autoritarismo e foco na industrialização nacional, envolvendo, mesmo que de maneira desigual, a burguesia e as classes populares. Pacto esse que, ao se finalizar, com a consolidação de um capitalismo industrial, contribuiu na transferência do poder político para um grupo da classe média composto por industriais, políticos tecnocratas e militares. Essas associações são muito bem resumidas por Bresser-Pereira:

O comando coube a um político autoritário e nacionalista, herdeiro do positivismo que esposara na juventude, cujas ideias liberais, importadas da Europa, cederam à realidade de um país que não havia ainda realizado sua revolução nacional, mas apenas sua Revolução Mercantil. Getúlio Vargas liderou uma coalisão política heterogênea, a Aliança Liberal, para realizar a revolução, e, depois, gradualmente, sem plano mas com sentido de oportunidade, grande capacidade de conciliação e visão do futuro, estabeleceu uma nova coalisão política baseada na aliança entre os setores substituidores de importação da velha oligarquia, empresários industriais, os técnicos e os militares do governo, e os trabalhadores urbanos (BRESSERPEREIRA, 2015, p. 113).

A ferramenta usada por Vargas para blindar o Estado contra a volta ao poder das oligarquias agrárias exportadoras, foi o autoritarismo. Santos (1978) o define como “autoritarismo instrumental”, que se caracteriza por um Estado autoritário, politicamente centralizado, com a finalidade de garantir a organização política desejada. Esse "autoritarismo instrumental" apontado pelo autor ainda possibilitaria o alinhamento entre a esfera jurídicapolítica e a formação da nacionalidade, indo na contramão de outros autores que afirmavam que a elite nacional tinha vocação liberal. A expectativa era que esse autoritarismo instrumental gerasse condições necessária para uma organização social "democrática", ainda bastante restrita se remetendo à obra de Oliveira Viana (1974) com foco entre 1930 e 1940.

Em uma visão retrospectiva, não causa tanta estranheza que, neste contexto, ao final de 1937, temos uma Constituição outorgada e a instauração da ditadura do Estado Novo. Essa 
nova constituição trouxe em sua essência os moldes fascistas de organização institucional empregados em outras partes do mundo na época. Ela reforçava uma tendência, que vinha desde 1930, de uma economia com intervenção direta do Estado e que, com essa carta magna, ganhou força para criação de órgãos que reforçasse esse modelo.

Uma vez que o cenário internacional pode ser um dos condicionantes do cenário doméstico, os acontecimentos internacionais que se seguiram pós crise de 1929, acabaram por contribuir, mesmo que contraditoriamente, nos processos de formação e consolidação do Estado em termos gerais e das organizações multilaterais, de maneira mais específica. É nesse contexto que, em julho de 1944, ainda em plena Guerra, líderes de 44 países (incluindo uma delegação brasileira, encabeçada pelos senhores Evaldo Lido, Arthur de Souza Costa, Eugênio Gudin, Octávio Gouveia e Roberto Campos) se reuniram na cidade de Bretton Woods, estado de New Hampshire, com a finalidade de traçar diretrizes para uma nova ordem econômica global. Segundo Carneiro (2002), o acordo de Bretton Woods estabeleceu regras mais incisivas sobre a mobilidade de capitais, aumentando suas restrições e, com isso aumentando também a capacidade de se fazer de políticas econômicas internas com maior grau de autonomia, em especial nos países em desenvolvimento.

A maneira como se finaliza a II Guerra reposiciona a geopolítica internacional, por meio de um ambiente belicoso, tenso e todo o receio que ele gerou. Como legado da guerra, acirram-se as divergências entre os Estados Unidos e seus aliados de um lado e a URSS de outro, instaura-se, a partir de 1947, um período conhecido como Guerra Fria. A arena não se restringia mais ao campo militar, se alastrando nos campos econômico, político e ideológico de cada bloco. Esses blocos se separavam fundamentalmente e conhecidamente como países capitalistas de um lado e o bloco socialista de outro.

Fato efetivo é que a Guerra Fria foi uma engrenagem de conflitos, tendo ficado evidenciado o posicionamento dos Estados Unidos de repelir qualquer tentativa de governos à 
esquerda, a partir de altos investimentos na industrialização de sua periferia ou intervenções militares em nome da democracia e da liberdade. No bojo das medidas econômicas encabeçada pelos EUA merece destaque o Plano Marshall, colocado em prática em 1947.

Com o nobre objetivo de contribuir com a reconstrução dos países capitalistas destruídos, além de ajudá-los a se recuperar e reorganizar, buscando o fortalecimento da relação comercial entre eles e os Estados Unidos, o que se assistiu foi o aumento das exportações de produtos e capitais estadunidenses e a expansão de sua influência política e militar pelo mundo1. Em outras palavras, o "plano Marshall seria a reprimarização das economias Latinoamericanas e o fim do sonho da autonomia nacional" (CEPÊDA, 2014, p. 05). Coincidindo com a derrota do eixo nazifascista na Europa, no Brasil se encerra o período do Estado Novo e com seu fim, o surgimento de novos partidos políticos que irão materializar a grande heterogeneidade dos interesses das diversas frações de classes presentes no país.

A democracia brasileira do período, notadamente de 1946 até o golpe de 1964, segundo Azevedo (2014), é uma democracia com grandes déficits tanto em relação a participação eleitoral quanto a inclusão social e políticas relevantes para grupos sociais desprivilegiados como os da área rural. Todavia, pode-se salientar como avanços incorporados pela Constituição de 1946, a fixação do mandato do presidente em 5 anos, ampliação do voto feminino, ajustes na representação dos estados menores na Câmara dos Deputados, o fortalecimento das ações do Congresso e o restabelecimento da divisão e atribuições e responsabilidades entre união, estados e municípios entre outras medidas.

A partir de meados da década de 1950 o país assiste a complexificação de sua industrialização, passando de uma industrialização leve ou restringida que se estendeu de 1930 até mais ou menos 1955 para uma industrialização pesada que se inicia com Kubitschek e se

${ }_{1}$ Cabe destaque à Lincoln Gordon como colaborador e implementador do Programa Econômico de Recuperação Europeia (Plano Marshall) que terá um papel fundamental nas relações Brasil e Estados Unidos, a partir de 1961, sendo um dos grandes articuladores do golpe de 1964. 
estende, grosso modo até a crise da década perdida. Em síntese, até meados da década de 1950, a mudança mais significativa na economia brasileira é a suplantação do setor agroexportador pelo setor industrial, setor esse que passa a ser determinante o eixo dinâmico da economia, com forte presença do Estado na construção da indústria de base. A partir da segunda metade dos anos 1950, rompem-se os constrangimentos à industrialização nacional em bases mais capitalistas, típicos da fase anterior, dados pela fragilidade das bases técnicas e financeiras do capital (CANO, 1998; CARVALHO, 2004; 2017). Mas, de forma efetiva tínhamos um Estado "pobre" que arcava com altos custos dessa industrialização, que acabou por gerar inflação e endividamento, notadamente externo.

Importante observar que, do ponto de vista ideológico, com a Guerra Fria, o Brasil, já na década de 1950, se confrontava com a dicotomia ideológica entre esquerda e direita. Uma parcela considerável da população, de origem diversa que se fragmentava em também em diversos grupos sociais, lançava o debate para uma sociedade dita mais justa, com o objetivo de implantar as reformas de base. Em contrapartida o "fantasma do comunismo" já rondava a burguesia nacional. O conflito de classe estava presente no cotidiano nacional.

Em 1960 são empossados Jânio Quadros e João Goulart, apresentando forte crítica à lógica de condução do governo anterior, especialmente à ineficiência administrativa e responsabilidade pelos altos índices de inflação e elevada dívida externa. De maneira inusitada, os poucos meses do governo Quadros foi caracterizado pela excentricidade dos atos do presidente, que acabou por renunciar menos de 7 meses após tomar posse. Os fatos que decorrem da renúncia de Jânio Quadros até a posse de João Goulart são devera conhecidos, cabendo aqui alguns comentários do ambiente político e social do período. Era, por excelência, um período conturbado internamente, a movimentação política era evidente, com destaque para a articulação dos movimentos sociais, sindicatos e, inclusive, as ligas camponesas, que tinham como objetivo: 
(...) transformar as ligas em um partido revolucionário de base agrária capaz de disputar a hegemonia política no campo da esquerda e influenciar os mesmos à liderar o que a esquerda na época definiam como revolução brasileira...manter a organização de massa paralela à organização política (AZEVEDO, 2007, p. 39).

A partir de 1963, depois do plebiscito que reestabelece o presidencialismo no Brasil, com Goulart como presidente, a luta política se agrava, pendendo para a radicalização, os conflitos reproduzem cada vez mais a oposição entre esquerda e direita e as direitas civis e militares passam a se organizar para o confronto, com destaque para o Instituto de Pesquisas e Estudos Sociais (IPES) e o Instituto Brasileiro de Ação Democrática (IBAD), ambos de cunho anticomunista. No mesmo momento histórico em que as organizações sindicais e estudantis confrontavam o governo, novas organizações conservadoras se aliavam a antigas organizações como às ligadas ao latifúndio, com o objetivo de derrubar o governo e instaurar uma nova ordem nacional, vista com bons olhos pelo governo estadunidense. Em contraposição, mesmo com as tentativas de unificar e fortalecer a oposição, ainda era notória a fragilidade da unidade de esquerda (CARVALHO, 2002).

\section{DO CONTEXTO GERAL À CONTRIBUIÇÃO DO AUTOR}

É em meio a todo esse contexto que, em 1955, será criado o do Instituto Superior de Estudos Brasileiros (ISEB), que terá como função agremiar intelectuais para refletir sobre o processo mais geral de desenvolvimento e suas contradições. Dentre esses intelectuais estava Wanderley Guilherme dos Santos.

Interessante observar que o ISEB é precedido pelo Instituto Brasileiro de Economia, Política e Sociologia (IBESP) constituído, em parte, por um grupo denominado Grupo de Itatiaia, composto por intelectuais tanto do Rio de Janeiro como de São Paulo, que se reuniam na cidade de Itatiaia, meio do caminho de ambos os estados. O grupo primava, conforme 
evidenciado por Bariani (2005), pelo impulsionamento de um pensamento genuinamente nacional que, nas palavras de um dos mais emblemáticos membros, Hélio Jaguaribe, tinha “[...] a vontade de compreender a correlação entre uma visão geral da cultura universal e a problemática brasileira em sua especificidade" (2005, p. 31).

Em 1955, com respaldo do executivo federal, por meio da ampliação de escopo e ação do IBESP, nasce o ISEB, através de decreto de João Café Filho, vinculado ao Ministério da Educação e Cultura, com a função de promover curso, conferências e publicações. Todavia os intelectuais que o compunham mantinham a ideia de um estudo aprofundado da realidade brasileira.

Ao longo de sua existência é possível três fases do ISEB, a saber: uma primeira caracterizada por posições ideológicas ecléticas e conflitantes, uma segunda que tinha uma convergência para a ideologia nacional-desenvolvimentista e uma teceria, da qual fez parte Wanderley Guilherme dos Santos, que pensou o movimento político em torno das reformas de base (SILVA, 2013). Assim, o período que se abre em 1962, evidencia o ISEB enquanto ator político em conflito.

O grupo passa a ter velhos ISEBianos representados por Werneck Sodré e Vieira Pinto e novos ISEBianos, como Wanderley Guilherme dos Santos. Essa chave analítica mostra um instituto mais ativo no que tange a formação popular, tanto na promoção de conferências avulsas quanto na intervenção junto aos Centros Populares de Cultura que atuavam nas classes populares, na tentativa de construir uma cultura nacional popular e democrática, pelo menos até o Golpe de 1964. Será neste ínterim, que nascerá os Cadernos do Povo Brasileiro, que em seu quinto volume apresentará, em 1962, o artigo que abre a trajetória intelectual de Wanderley Guilherme dos Santos, com o título: Quem dará o golpe no Brasil? 
Quando analisamos a obra e o posicionamento de Wanderley Guilherme dos Santos, quanto à sua trajetória, evidenciamos um intelectual em transformação que transita entre a filosofia, sociologia e a ciência política. Para Moreira (2011):

[...] pode-se afirmar que a obra de Wanderley Guilherme dos Santos tipifica, como outros de sua geração, a própria transformação pela qual passou o pensamento político-social brasileiro da primeira para a segunda metade do século XX. O autor, ligado originalmente ao PCB (Partido Comunista Brasileiro) e ao ISEB (Instituto Superior de Estudos Brasileiros), ainda que bastante crítico das posições hegemônicas nos mesmos, formado num contexto histórico e semântico em que o marxismo e o nacionaldesenvolvimentismo eram as forças intelectuais dominantes, inicia sua trajetória intelectual, no princípio dos anos 60, elaborando análises sociológicas da realidade brasileira e daí derivando as consequências para a política, se constitui, em meados da década de 70, em um "cientista político", no sentido moderno e acadêmico do termo, reivindicando autonomia para os fenômenos e variáveis propriamente políticas. (MOREIRA, 2011, p. 02)

Evidentemente que esse posicionamento mais à esquerda e a proximidade com movimentos e lutas populares colocam o ISEB em evidência nos meios militares2. Por consequência, com o golpe, ele foi imediatamente fechado, tendo sido instaurado inquérito para apuração de suas atividades e a apreensão de todos os documentos, arquivos e publicações ali arquivadas. Dentro desse contexto, dos impedimentos e limitações que imperaram pós golpe de 1964, muitos recém graduados da época se viram diante da impossibilidade de construir ou desenvolver uma trajetória acadêmica, entre estes estava Wanderley Guilherme dos Santos que foi para os Estados Unidos se doutorar na Universidade de Stanford, até 1969.

Uma outra atuação de Guilherme dos Santos foi ser um dos fundadores do Instituto Universitário de Pesquisas do Rio de Janeiro (IUPERJ), criado em 1969, sendo um refúgio

\footnotetext{
2 Hélio Jaguaribe (2005), um dos nomes mais importantes da primeira fase do ISEB, diz que esse posicionamento dos integrantes junto a camada popular e ideias mais à esquerda foram responsáveis por tornar o ISEB "um eco do PC". O descontentamento de Jaguaribe quanto a essa aproximação também é evidenciado em entrevista concedida, em março de 1988, na qual ele afirma: "na verdade, o final do ISEB, a meu ver não foi feliz, porque foi arrastado por uma visão primária do marxismo barato, do comunismo de tipo muito fácil, e se tornou órgão de 'agit prop' e não um centro de pensamento. (...) na verdade, no final, o ISEB era um eco do PC, não tinha mais vida própria” (JAGUARIBE,1988, p. 12).
} 
para intelectuais comprometidos com a democracia brasileira e como um espaço de reflexão, debate e construção de uma democracia nacional consolidada e substantiva3. Para Moreira (2011), na trajetória deste autor pode-se identificar três fases distintas:

\begin{abstract}
A primeira fase (1962-63) denominamos de "Análise Socioeconômica e Crítica das Ideologias Brasileiras", na qual o autor ainda não figura como um cientista político propriamente dito; a segunda (1967-88), "Ciência Política: Autoritarismo e Redemocratização", posterior, portanto, à sua formação no exterior no campo de conhecimentos em que se consolidaria como intelectual; a terceira (1990-2008), "Ciência política: a poliarquia brasileira", marcada basicamente pela centralidade da democracia como objeto - entendida, nos termos de Robert Dahl, como um regime político marcado por elevada liberalização [competição pelo poder] e participação política - e como ideal político do autor (MOREIRA, 2011, p. 311)
\end{abstract}

Nesta perspectiva, na trajetória do autor, ele lança mão de elementos do marxismo que vão além dos conceitos básicos trazidos pela ideologia em si, como conceitos de classes sociais, avançando nas representações das relações humanas como determinantes da condição objetiva do real.

Sustentando por esta visão, ele consegue antever e analisar um golpe inevitável, pelas condições socioeconômicas do país e pela condição intrínseca que abre a necessidade real de um governo "forte" acima dos partidos, para guiar uma nação fraca. Ao mesmo tempo em que sua obra é carregada pelo princípio basilar de crítica e confronto aos apoiadores do golpe, ele também faz duras críticas ao desenvolvimentismo, vendo a iniciativa dos intelectuais de abraçar a massa como um ponto fraco do processo de desenvolvimento.

A crítica do autor ao desenvolvimentismo se dá pelo determinismo histórico e, principalmente, porque toda vez que a autonomia é substituída, a pluralidade imponderável das relações humanas se coloca dentro de um paradigma teleológico.

3 Para maiores informações sobre o IPERJ acessar: http://www.iuperj.br/ 
Em Sessenta e quatro: a anatomia da crise, sua tese de doutorado, que nasce simultaneamente com a consolidação da moderna ciência política brasileira, fica evidente uma abordagem que se distancia da sua primeira obra. Observa-se um deslocamento dos elementos marxistas, passando o autor a dar mais atenção e ênfase às instituições e à autonomia da política. A obra apresenta uma estruturação empírica que se destaca nas obras nacionais da época, fortemente apoiada nos dados estatísticos, o que não era comum nas obras nacionais da época. Esse legado o autor traz das relações e período de vivência nos EUA.

De forma mais ampla, a essa obra abre uma nova métrica para o estudo dos fenômenos políticos. Ela aponta que, até os anos 1970, o golpe não havia sido estudado de forma profunda, principalmente porque os intelectuais que até ali se propuseram a fazê-lo tinham como fundamento da análise o "paradigma clássico de análise social e política brasileira" (SANTOS, 1986, p. 18). Segundo Moreira (2011), a tese aponta as reflexões anteriores como generalizantes e classifica essas análises principalmente como incapazes de captar as especificidades políticas do período.

A tese basilar utilizada é que o golpe se deu devido a "paralisia decisória" e que, em detrimento de uma política estática, ele seria inevitável. A explanação do autor busca compreender um momento histórico específico, lançando mão de mecanismos causais para investigar as estruturas políticas que geriram o golpe. As origens do golpe, para Santos, se originaram de uma grave crise tanto do legislativo quanto do executivo. Os dados do autor apontam para um conflito acirrado pré e pós 1964 entre os partidos, anulando as possíveis decisões do Congresso. Todavia, essa crise política não ficou insulada, ela também atingiu o executivo que tinha pouca influência no legislativo. Dessa forma, esse cenário de estagnação (paralisia) dos tomares de decisão foi superado por uma intervenção externa, que nesse caso específico ocorre pelo golpe militar. 


\section{CONSIDERAÇÕES FINAIS}

Seria impossível falar da obra Sessenta e quatro: a anatomia da crise sem antes fazer a contextualização e uma recuperação histórica nacional e internacional do Brasil até 1964. As mudanças no cenário internacional impactaram fortemente na estruturação e desenvolvimento do cenário brasileiro e, também, no da América Latina pós Segunda Guerra Mundial. No caso específico do afastamento do autor com o nacional-desenvolvimentismo, isto se deveu em função do caráter estrutural e determinista desta teoria, na avaliação de Guilherme dos Santos, tendo a nação o dever inexorável do desenvolvimento e a superação do atraso.

No conceito de "paralisia decisória " o autor está deixando claro que não adianta se ter o nacional-desenvolvimentismo se, na prática, as relações nacionais que envolvem relações, regiões, capitais nacional e internacional, frações de classes que existem dentro da sociedade brasileira, estão incrustadas nas relações entre legislativo, executivo e judiciário. Na Ciência Política como entendemos hoje, o autor estava falando do campo das ações e instituições.

\section{REFERÊNCIAS}

AZEVEDO, F. A. Revisitando as ligas camponesas. In: FILHO, J. R. M. (Org). O golpe de 1964 e o regime militar: novas perspectivas. São Carlos: Edufscar, 2014.

BARIANI, E. Uma intelligentsia nacional: grupo de Itatiaia, IBESP e os Cadernos de Nosso Tempo. Caderno CRH, v. 18, n. 44; pp. 249-256, 2005.

CANO, W. Desequilíbrios Regionais e Concentração Industrial no Brasil, (1930-1970; 1970-1995). 2 ed. Campinas: Unicamp/IE, 1998.

CARNEIRO, R. Desenvolvimento em Crise: a economia brasileira no último quarto do século XX. São Paulo: Editora Unesp, 2002.

CARVALHO, J. G. Integração e dinâmica regional: o desenvolvimento recente da região administrativa de São José do Rio Preto (1980-2000). Tese de dissertação. Unicamp.

Campinas, 2004.

CARVALHO, J. G. Economia política e desenvolvimento: um debate teórico. Coleção governança e desenvolvimento. Grupo de Pesquisa em Ideias, Intelectuais e Instituições, UFSCar: 2017. Disponível em: https://pt.scribd.com/document/358008817/EconomiaPolitica-e-Desenvolvimento-um-debate-teorico. Acesso em: 22/04/2020. 
CARVAlHO, J. M. Cidadania no Brasil: o longo Caminho. $3^{\mathrm{a}}$ ed. Rio de Janeiro: Civilização Brasileira, 2002.

CEPEDA, V. A. Estado, democracia e intelectuais na obra de Roberto C. Simonsen (19331948), In: Anais do IX ENCONTRO DA ABCP, Brasília. 2014. Disponível em: <http://www.encontroabcp2014.cienciapolitica.org.br/resources/anais/14/14099 64494_ARQUIVO_Estado,democraciaeintelectuaisnaobradeRobertoC.Simonse n_ABCP_2014.pdf>. Acessado em: 21/09/2019.

JAGUARIBE, H. O ISEB e o desenvolvimento nacional. In: TOLEDO, C. N (org.). Intelectuais e política no Brasil: a experiência do ISEB. Rio de Janeiro: Revan.2005.

KUMASAKA, H. B.; BARROS L. Entrevista com o professor Hélio Jaguaribe de Mattos. In: História da Ciência (Depoimentos orais realizados pelos Arquivos Históricos do CLE/ Unicamp) Campinas. 1998. Disponível em http://www.cle.unicamp.br/arquivoshistoricos/ehelio.pdf.

LIMONGI, F. P. Resenha: Sessenta e quatro: anatomia da crise Sessenta e quatro: anatomia da crise - de Wanderley Guilherme dos Santos. São Paulo: Vértice, 1986. In: Rec. Bras. Ci. Soc. v.2, n.4 - São Paulo. 1987. Disponível em:

<http://www.anpocs.org.br/portal/publicacoes/rbcs_00_04/rbcs04_resenhas.htm > Acesso em:04/03/2020.

LOPES, L. S. Dicionário Histórico Biográfico Brasileiros pós 1939. Rio de Janeiro: Ed. FGV, 2001.

MOTTA, R. P.S. O anticomunismo militar. In: O golpe de 1964 e o regime militar: novas perspectivas. In: FILHO, J. R. M.(Org.) São Carlos: Edufscar, 2014.

OLIVEIRA VIANNA, F. J. Problemas de Política Objetiva, $3^{\text {a }}$ ed. Rio de Janeiro: Record Cultural, 1974.

SANTOS, W. G. A práxis liberal no Brasil: propostas para reflexão e pesquisa. In: Ordem burguesa e liberalismo político. São Paulo: Duas Cidades, 1978.

SANTOS, W. G. Quem dará o golpe no Brasil? Cadernos do povo brasileiro. Disponível em: http://novo.fpabramo.org.br/uploads/quemdaraogolpe.pdf. Acesso em: 13 abril 2020.

SANTOS, W. G. Sessenta e Quatro: Anatomia da Crise. São Paulo: Vértice, 1986.

SILVA, F. X. A formação do Brasil moderno em dois tempos: uma análise comparada do pensamento de Oliveira Vianna e Hélio Jaguaribe. Tese de doutorado. Unicamp. Campinas. São Paulo, 2013.

STEIN, L. M.; SAPIA, R. Ciências Sociais e trajetória intelectual: entrevista com Wanderley Guilherme dos Santos. Estudos de Sociologia, v. 9, n. 16, 2004. Dossiê Octávio Ianni. Disponível em: <http://hdl.handle.net/11449/106936>. Acessado em: 20 abril 2020. 
WHITEHEAD, L. A organização do Estado na América Latina após 1930. In: BETHEL, L. (Org.).História da América Latina: Volume III. América Latina após 1930: Estado e Política. São Paulo: Edusp, 2009. 